\title{
PERCEPÇÃO SOBRE O HÁBITO ALIMENTAR ENTRE ESTUDANTES DE NUTRIÇÃO
}

\author{
Eliane Garcia REZENDE ${ }^{1}$ \\ Nara Garcia D'AVILA ${ }^{2}$ \\ Keiko Maly Garcia D'Avila BACARJI ${ }^{3}$ \\ Nadja Maria Gomes MURTA ${ }^{4}$
}

\begin{abstract}
${ }^{1}$ Professora adjunta da Universidade Federal de Alfenas (MG).Possui graduação em Nutrição e em Farmácia Bioquímica pela Universidade Federal de Ouro Preto; Doutora em Ciências Sociais pela PUC/SP, área de antropologia e Mestre na área de Epidemiologia, pela Universidade Federal de Minas Gerais. elianeg1202@gmail.com

${ }^{2}$ Nutricionista formada da Universidade Federal de Alfenas (Unifal-MG). narabacarji@gmail.com

${ }^{3}$ Psicóloga. keikodavila7@gmail.com

${ }^{4}$ Nutricionista, Doutora em Ciências Sociais, Professora da Universidade Federal dos Vales do Jequitinhonha e Mucuri. nadjamurta@gmail.com
\end{abstract}

Recebido em: 30/05/2014 - Aprovado em: 25/09/2014 - Disponibilizado em: 15/12/2014

\section{PERCEPTION ABOUT FOOD HABIT AMONG NURSING STUDENTS}

\begin{abstract}
Resumo
O hábito alimentar sofre muitas influências durante o percurso da vida. Realizar a formação universitária no curso de nutrição poderá ser motivação extrínseca para mudança de hábito alimentar? Esse estudo qualitativo procurou responder essa questão, e apresentou como objetivo conhecer possíveis interferências no hábito alimentar e estilo de vida de estudantes do Curso de Nutrição após percurso acadêmico universitário. Realizado na Unifal-MG, com estudantes do último período do curso, utilizou-se de entrevistadas semiestruturadas e gravadas na tentativa de compreender o hábito antes e após estar concluindo o curso e delinear os fatores motivadores de mudanças. Por análise de conteúdo das entrevistas, foi possível verificar uma visão reduzida sobre hábito alimentar. Percebeu-se que as relações sociais e os aspectos afetivos foram relevantes como motivadores extrínsecos da mudança do hábito entre as estudantes. Os conhecimentos adquiridos durante o curso de nutrição pouco interferiram na mudança de conceitos e hábitos, e o modelo biomédico gerou medo de adoecer quando permitiu a visão biológica da relação alimento e doenças, representando motivação de mudanças para poucos estudantes. O estudo das representações sociais circundando estes aspectos pode ser especialmente útil para pensar programas de promoção da saúde e Educação Alimentar e Nutricional. Palavras-chave: Hábito Alimentar. Estudante. Nutrição. Motivação extrínseca.
\end{abstract}

\begin{abstract}
Abstrat
Alimentary habits suffer great influence during lifetime. Can university education in nutrition be extrinsically motivator for alimentary habit changes? This qualitative study aimed at answering this question, and was directed at knowing the possible interferences in the alimentary habits and lifestyle from the Nutrition Course students after their academic path. Performed at Unifal-MG, with college students from the last year of school, semi-structured interviews were used and recorded in the attempt of understanding their habits before and after the conclusion of the course, as well as profiling the motivating factors for changes. Through the content analysis of the interviews it was possible to observe a reduced view on alimentary habits. It was noticed that social relations and affective aspects were relevant as extrinsic motivators for change of habits among students. The knowledge acquired during the Nutrition Course scarcely interfered in the change of concepts and habits. The biomedical model generated fear of illness when it permitted the biological view of the relation between food and disease, representing motivation for change in few students. The study of the social
\end{abstract}


representation surrounding these aspects may be particularly useful to reason health promotion programs as well as Nutritional and Alimentary Education.

Keywords: Food habit. Student. Nutrition. Extrinsic motivation.

\section{Introdução}

A alimentação está inserida em um complexo aspecto pluridimencional, em que crenças, tabus, saberes, sentimentos da vida cotidiana, rituais, valores individuais e coletivos do sagrado e do profano, se misturam e permeiam a relação do indivíduo com sua refeição (REZENDE, 2011). Na representação da alimentação saudável estão envolvidos diversos fatores desencadeadores da busca pelo alimento, pois mais do que a oferta de nutrientes, $\mathrm{o}$ ato de se alimentar engloba costumes e crenças criados desde a infância. Desde a amamentação a criança estabelece uma relação afetiva por meio de seu primeiro alimento, o leite. A partir do desmame há um preparo à valorização e ao gosto pelo alimento a partir do laço emocional já construído pela, e com a família, que cria e recria valores culturais.

A alimentação é motivada por diversos fatores, muitos deles distanciados da ciência da nutrição propriamente dita. Fatores como o início e a manutenção das relações pessoais, a expressão de amor e carinho, a reação diante de situações estressantes (seja de cunho psicológico e/ou emocional), o significado de status social, recompensas ou castigos, mudanças geográficas, dentre outros, afetam o hábito alimentar (NASCIMENTO, 2007). Nas palavras de Freitas:

O alimento para o ser humano tem
historicidade nas mais diversas
sociedades em que se cria, destrói,
modificam hábitos, incorporam outros
valores, religiosidades e tantas mágicas e
crenças que existem em torno do comer
(FREITAS, 2008, p.307). Nesse sentido a vida acadêmica nas universidades pode, e tem auxiliado na formação de novos hábitos alimentares, por ser um ambiente onde estão envolvidos tanto os fatores relacionados ao aprendizado escolar formal, como aqueles que envolvem o suporte físico e financeiro (ALVES, BOOG, 2006).

O início do aprendizado sistemático da nutrição deve ser uma fase importante na formação de profissionais Nutricionistas, para que consigam compreender e relacionar o indivíduo ao alimento de maneira ampla, valorizando não só os aspectos biológicos da nutrição como também as questões socioculturais individuais (GARCIA, 2005).

A partir dessa perspectiva, estudar sobre alguns aspectos que permeiam as mudanças no comportamento e hábito alimentar de universitárias do curso de nutrição pode ser relevante para nortear práticas de Educação Alimentação e Nutricional. Realizar o curso universitário em Nutrição, que tem como foco a relação do ser humano com o alimento, 
pode exercer motivação extrínseca de mudança de hábitos?

Para analisar esta perspectiva, o objetivo deste presente estudo foi o de conhecer possíveis interferências no hábito alimentar e estilo de vida de estudantes do Curso de Nutrição após percurso acadêmico na universidade.

\section{Fundamentação metodológica}

Para remontar a construção histórica dos significados que as mudanças desencadeadas pela vida escolar, o encontro entre os sujeitos (pesquisador e pesquisado) precisa permitir um diálogo, e a entrevista semiestruturada foi utilizada para possibilitar esse estudo. Relatar as alterações ao longo do período; dialogar sobre as percepções do alimento e da alimentação; revelar os aspectos simbólicos que permeiam esta relação é sem dúvida um desafio. Assim, o estudo utilizou a metodologia qualitativa, na busca por compreender e não somente descrever os fenômenos ligados às crenças e aspectos subjetivos ao objeto em estudo (MARTINS, BÓGUS, 2004).

As informações foram coletadas entre estudantes universitárias do curso de nutrição da Universidade Federal de Alfenas (AlfenasMG). O critério de inclusão foi estar no último período do curso, pois o sujeito já teria passado por todo processo de influência acadêmica, tanto de vida universitária, quanto por estar exposto aos conteúdos de disciplinas que permitem a formação do profissional Nutricionista.

Para estudos, que buscam abrangência e aprofundamento na compreensão do significado, o tamanho da amostra não apresenta necessidades estatísticas. O limite para o número de entrevistas é dado pelo critério de saturação de respostas, ou seja, no momento em que começa ocorrer redundância ou repetição de conteúdo. As entrevistadas foram todas do gênero feminino, pois particularmente nesta turma de formandos não havia masculinos. Foram entrevistadas dez acadêmicas, moradoras de república, que serão identificadas com a letra "N", representando a palavra Nutricionista, e sequência numérica de transcrição - N1 a N10. A participação, de forma voluntária, ocorreu mediante a assinatura do termo de consentimento informado, segundo critérios éticos da Resolução 196/96 para pesquisas com seres humanos (BRASIL, 1996), após aprovação pelo Comitê de Ética em Pesquisa em Humanos da Unifal-MG (protocolo $\mathrm{n}^{\circ}$ 81/2011). As entrevistas foram realizadas na própria universidade, ou no domicílio. Foram gravadas e transcritas, depois sofreram adequação à língua portuguesa vigente.

A fundamentação teórica para análise dos dados foi sustentada por Bardin (2011), considerando análise de conteúdo. Fez-se a estruturação por categorias na busca de atingir os significados manifestos e latentes das 
ideias e expressões. As categorias estabelecidas observaram os princípios de serem mutuamente exclusivas; a possibilidade de incluir qualquer resposta em uma das categorias e respeitarem um único princípio de classificação. Nas manifestações, o significado foi o objeto central da investigação, e recebeu ordenação nas categorias: 1) hábito alimentar antes e após ingresso na universidade; 2) conceito de hábito alimentar saudável e 3) mudanças no comportamento alimentar por estar realizando o curso de nutrição.

\section{Alimentação antes e após ingressar na Universidade}

"Alimentar-se é um ato nutricional, comer é um ato social” (SANTOS, 2005, p.12).

Como já estabelecido na literatura, o homem atribui diferentes significados ao alimento e à comida. Essas representações estão presentes em rituais religiosos, festividade de passagem do ano gregoriano, confraternizações, etc., onde estão envolvidas relações sociais. O convívio social criado e mantido durante as refeições familiares, nas trocas de informações ou nos momentos de encontros rico e prazeroso demonstram o lado afetivo da alimentação (ROMANELLI, 2006).

A mudança do comportamento alimentar pode ser desencadeada por motivações de origem intrínseca ou extrínseca. As intrínsecas são quando a pessoa por sua autoestima resolve alterar hábitos de forma a melhorar suas expectativas de saúde. Nas motivações extrínsecas a mudança ocorre vinculada ao apoio familiar, estímulos de amigos, de profissionais da saúde, ou outros externos à pessoa.

O termo hábito alimentar vem sendo utilizado para designar os costumes e o modo de se comer de uma pessoa ou comunidade, sendo influenciadas pela cultura, condições socioeconômicas, relações sociais, relações afetivas, dentre outras. Desde a infância são moldados partindo do convívio familiar, do cuidado e preocupação com uma alimentação adequada, criando assim, lembranças acolhedoras que irão se conservar durante toda a vida. Como diz Nascimento (2007):

Comemos lembranças da família, comemos história e comemos valores culturais. A primeira sensação que o paladar vivencia é o leite do seio da mãe. Ingere com o leite, amor, carinho e bemestar. É, portanto, a sensação interior de prazer que fica marcada como tatuagem para o resto da vida. Muito comum é ouvirmos alguém dizer: 'tem gosto de infância'... Ou como se costuma dizer, comida de infância é quitute ao qual recorremos quando desejamos nos sentir reconfortados, como carinho de mãe e colo de avó. Nascimento (2007, p.72)

Esta manifestação de afeto familiar é recorrente nas falas das entrevistadas, como N9 diz:

Quem, às vezes quando está doente, não quer consumir uma sopa da mãe? É um alimento aquecedor, que te acolhe, te aquece e te traz felicidade. (N9) 
Pesquisadores da psicologia, verificaram que preferências alimentares infantis são mantidas até a fase adulta (MORGANA, VECCHIATTIA, NEGRÃO, 2002). Na educação familiar os pais geralmente usam alimentos não nutritivos (balas, chocolates, etc.) como recompensa para influenciar comportamentos dos filhos, mediante a prévia alimentação de vegetais, legumes ou frutas. Crenças passam a ser formadas sobre os alimentos nutritivos, os quais terminam por serem menos desejados (STRAUB, 2005). Já se verificou que os usos dessas estratégias coercitivas são falhas, visto o aumento de "comportamentos aversivos pela criança diante da comida-alvo" (STRAUB, 2005, p.538).

A situação de uso de alimentos não nutritivos foi encontrada nas entrevistas atreladas à sensação de prazer, em que a alimentação familiar oscilava entre o considerado saudável e a prática de ingerir alimentos sem pensar na saúde. $\mathrm{O}$ relato de $\mathrm{N} 2$ trouxe de forma mais clara essa perspectiva, e diz que ao entrar na universidade houve mudanças nesse padrão de alimentos considerados ruins.

Então, eu comia pouquíssima fruta, pouquíssima verdura e tal, só no almoço. Nos horários que eu estava no meio, comia essas 'bobajadas' todas. (...) Quando eu vim pra cá, tive essa oportunidade de mudar, porque todo mundo comia em restaurante, comia na faculdade. (...). (N2)

Os universitários, em geral, elegem a mãe como provedora da alimentação antes da faculdade, representando, assim, a garantia de uma qualidade nutricional satisfatória e adequada, em suas casas (ALVES, BOOG, 2006). Quando perguntadas sobre os hábitos alimentares antes de iniciarem a vida universitária as estudantes relatam os cuidados maternos de uma alimentação saudável:

Assim na minha casa, minha mãe tem um hábito muito saudável sabe?! De comer muita verdura, muita fruta, muita coisa natural. (N1)

Antes eu comia todo o dia a comida da minha mãe (...) A minha mãe, ela gosta muito de cozinhar, ela também gosta muito de fazer preparação mais calórica, tipo doce, ela faz bastante doce, até mesmo a carne, o modo de preparar, ela sempre opta pelas opções mais calóricas. (...) Uma coisa que sempre foi boa na minha família é consumo de frutas e verduras. (N8)

Mas, entram na universidade, saem da casa materna, e passam por alterações em seu padrão social. As entrevistadas relatam as significativas mudanças depois de iniciarem a universidade, como na expressão de N3:

Quando vim pra cá, a menina com quem morei durante quatro anos, era muito certinha com alimentação, então, mudou pra melhor. A gente passou a comer menos fritura, a gente gastava bem menos óleo, menos sal, frutas, nossa, do que eu comia em casa eu passei a comer muito menos, então mudou pra melhor, nessa minha estadia em Alfenas. (...) Então aqui foi mais regulado, faço cinco refeições diárias. (N3)

Porém, alguns estudos têm demonstrado problemas em relação ao consumo alimentar de universitários, como a ausência de refeições, baixo consumo de frutas e leite, e a 
falta de cuidado com a própria alimentação (ALVES, BOOG, 2006). Perdem qualidade nutricional nas refeições e apresentam vulnerabilidade biológica devido a condições desencadeadas por modificações realizadas quanto ao estresse, consumo de bebidas alcoólicas, cigarros e a prática de exercícios físicos (VIEIRA, 2002). Outras situações cotidianas podem reforçar uma condição nutricional ruim, tais como: fatores psicossociais; condições em que o alimento foi conservado e/ou preparado antes do consumo; doenças que tenham relação com a nutrição e estilo de vida (VIEIRA, 2002; JACOBSON, 1998).

Segundo Borges e Lima Filho (2004, p.4) os estudantes, ao ingresso na universidade estão propícios a "novos relacionamentos, maturidade, maior raciocínio crítico, busca por sua identidade, tanto pessoal quanto profissional", motivações que pode gerar mudança na alimentação, inclusive por se sentirem livres para "tomarem suas próprias decisões em relação ao que comer, quando, onde e com quem comer".

Tais mudanças são percebidas pelas universitárias deste estudo, como pode visto na explanação abaixo:

Por vir pra uma cidade que a gente não tem tempo muitas vezes de ficar cozinhando, então muitas vezes a janta é leite e pão. (...) Mudou o almoço, mudou os hábitos, porque aqui, tem muitas outras responsabilidades, então tudo tem que fazer de acordo com o horário que você tem. (...) acabei por introduzir alimentos gordurosos, porque as vezes é mais fácil de fazer. (N 6)

A situação logística da vida universitária, ao apresentar responsabilidades antes não existentes aparece nas entrevistas, como justificativa para as restrições em conseguir uma alimentação regular. O pouco tempo para preparo das refeições, a distância entre a moradia e a universidade, o enfrentamento das intercorrências de morar longe da família, a dificuldade na divisão de tarefas da república com colegas de diferentes origens, são algumas das situações apontadas para a mudança do hábito, como bem exemplifica as colocações da estudante N5.

"Eu passei a não jantar, substituir o jantar por lanches, mas geralmente era assim bauru, ou as vezes salgado, mas não x-tudo, esses lanches. (...) Aqui na faculdade as vezes a gente passava sem almoço, de estar apertado. No começo da faculdade eu morava longe, então aí eu ficava aqui no centro, então as vezes eu comia salgado mesmo. (...) Todos dias eu comia fruta, diminui depois da faculdade. Daí agora no último ano também melhorei. Aí eu passei a comer mamão todo dia de manhã e pelo menos uma fruta durante o dia. (...) Mas antes já tive que ficar semanas, semanas sem comer uma fruta". (N5)

Citando Marcel Mauss, Alves e Boog (2007, p.202), diz que o "comer é um fato social total, ligando o social e o individual de um lado, o físico (ou fisiológico) e o psíquico de outro". O dividir, o "“repartir" implica em relações de troca, que vão muito além da quantidade, qualidade, procedência ou valor agregado do alimento repartido'. A partilha 
no "comportamento alimentar assegura um contrato social de identidades, estabelece a aliança e a comunhão" (dar, receber e retribuir). Nas relações de trocas misturam-se as vidas, os significados dos símbolos, "as pessoas e as coisas misturadas" gerando o "contrato e a troca" (ALVES, BOOG, 2007, p.202).

Nas entrevistas esses elementos de troca, de "mistura", de partilha, "a aliança e a comunhão" aparecem na perspectiva de motivação extrínseca para mudança da alimentação. Nas expressões da estudante N2, a convivência estimula a mudança e a troca:

Mudou ainda mais, primeiro pela
convivência com a menina que morava
na república, que foi outra visão de
alimentação, porque pra ela, o
aprendizado dela em relação à
alimentação, desde quando ela era
pequenininha era completamente
diferente (...) (referencia à colega
vegetariana). E eu comecei a ter contato
com isso, coisa que eu nunca tinha tido.
(N 2)

Influência dos estudos e o conceito de hábito alimentar saudável

Partindo da perspectiva de que hábito alimentar é construído desde a infância e influenciado pela identidade cultural, condição socioeconômica, religião e época em que se vive, é esperado que o conhecimento científico adquirido durante o curso de nutrição possa interferir nesse hábito alimentar. Espera-se que a combinação entre o novo conhecimento e as relações sociais estabelecidas no decorrer dos anos possa trazer efetivas alterações nos hábitos alimentares e de vida.

Em contraposição a essas inferências, nesse estudo percebemos que a aquisição de conhecimentos sobre alimentação e nutrição nem sempre foi apontado como variável significativa na mudança de hábitos. Como podemos analisar nos dizeres de N1:

Não mudou. Eu vou ser muito sincera nessa parte, eu acho a que a gente estuda nutrição, pra estudar doença. É uma nutrição paliativa, não uma nutrição preventiva.(...) Eu vejo mesmo na minha sala, praticamente ninguém mudou o hábito alimentar, praticamente todo mundo come besteira.(...) Mas não mudei, continuou a mesma ruindade de sempre. (N1)

Somente duas entrevistadas alegaram que o conhecimento adquirido no curso foi o fator na mudança de seu hábito alimentar. Nesses relatos enfatizam que a preocupação surgiu após realizar a disciplina de dietoterapia, e assim, estudar os processos patológicos interligados à alimentação.

O impacto causado pelo modelo biomédico, sustentado na visão biologicista é premente na ciência da nutrição, e ainda prevalece sobre as abordagens humanas e sociais das causas das doenças (BOSI, 1994). Ao abordar o tema no foco da patologia e terapia pela dieta, o faz de forma a desencadear o medo de adoecer e prioriza os aspectos do tratamento de doenças, nesse sentido, não ocorre a abordagem da promoção à saúde, nem vincula o prazer para 
a mudança de hábito alimentar. $\mathrm{Na}$ abordagem da entrevistada 8 (abaixo) percebe-se claramente essas premissas, ou seja, o receio de chegar à doença, referenciando exclusivamente o aspecto biológico atrelado à alimentação:

\begin{abstract}
Ah, se eu tivesse feito qualquer outro curso, eu não teria tido essa vontade de mudar. De uma hora pra outra eu disse 'não, preciso mudar'. Principalmente quando eu comecei as matérias de dietoterapia. A partir daí que, fiquei meio assustada, falei 'não olha, preciso mudar meu estilo de vida. (N 8)
\end{abstract}

Nas entrevistas, ao perguntar sobre o que seja alimentação saudável, observou-se uma homogeneização de conceitos atrelada a uma visão sobre $\mathrm{o}$ aspecto alimentar bem característico da ciência da nutrição enquanto modelo biomédico. Esse entendimento está reduzindo aos conhecimentos biológicos, em detrimento dos fatores sociais, psicológicos e culturais (COSTA, 2000). Em tal modelo os estudos focam os alimentos enquanto nutrientes em relação ao funcionamento biológico do corpo físico, o qual prioritariamente é difundido no curso de Nutrição, e foi evidenciado nas colocações das entrevistadas.

As respostas sobre hábito alimentar saudável se enquadraram no senso comum, que podemos classificar como conceito básico do processo, possuindo assim um significado superficial e irrefletido. Esse achado corrobora as afirmativas de Costa (2000, p.63) sobre a formação profissional que não articula os "conhecimentos biológicos com os sociais", e "reforçada pela deficiência de uma análise crítica da realidade". Trata-se de um posicionamento formado pela união de informações pacificamente assimiladas, sem uma reflexão crítica do objeto, como pode exemplificar claramente a seguinte fala:

Saudável? (...) É comer mais frutas, verduras, legumes, e menos alimentos industrializados. (...) E a prática também de atividade física. (N 8)

Entretanto, uma das respostas, se mostrou diferenciada sobre o tema saudável, mas assinala para uma conquista gerada pela experiência pessoal, e não necessariamente à formação acadêmica sistematizada. $\mathrm{O}$ convívio com outras pessoas de hábitos vegetarianos (namorado, colegas, amigos), pode ter contribuído para despertar novos interesses e perspectivas em relação à alimentação, gerando uma percepção mais ampliada do saudável:

O termo saudável é quase que igual a equilíbrio. Saúde para mim é equilíbrio. (...) É saúde mental, psicológica, social e porque não também uma alimentação equilibrada? Tudo que é demais, tudo que é desequilibrado passa a não ser saudável. (...) Alimentação saudável é alimentação equilibrada, sem medo, com cuidado, com carinho. (N 9)

Nesse caso, a visão sobre o conceito de hábito alimentar saudável, englobou aspectos físicos, psíquicos, sociais e espirituais, diferentemente da maioria das entrevistadas, que reduziu a abordagem como um fenômeno biológico/metabólico. 
É de longa data que a interação entre a alimentação e saúde é estudada, e por diferentes olhares, na tentativa de explicar o processo saúde-doença, juntando o saber científico às relações com o sagrado, admitindo que o corpo seja o meio para demonstrar o equilíbrio ou não com a natureza (SILVA， RECINE， QUEIROZ, 2002). Estudos atuais percebem a alimentação como uma das principais responsáveis pelas doenças crônico-degenerativas do mundo moderno. É possível observar uma grande ligação entre o hábito alimentar e o estilo de vida saudável como fatores preventivos de doenças. A alimentação saudável é relacionada não somente à dieta equilibrada e adequada, mas também às experiências vividas de cada sujeito, a relação com a promoção da saúde e não somente prevenção de doenças.

\section{CONSIDERAÇÕES FINAIS}

Pelos resultados encontrados, foi possível observar que o comportamento alimentar das estudantes, antes de ingressar na faculdade, estava condicionado ao hábito alimentar da família, não havendo uma preocupação na escolha e preparação dos alimentos, sendo estes, na maioria das vezes, elaboradas pela figura materna e inseridas em contexto de prazer familiar. Após a inserção na vida acadêmica, a influência das diferentes vivências, a nova rotina estabelecida pela faculdade, independência na escolha dos alimentos e a condição econômica longe da família, foram motivações extrínsecas para mudança no comportamento alimentar.

Este estudo mostrou que o conhecimento da ciência da nutrição pouco interferiu na mudança de hábito. As poucas mudanças relatadas foram decorrentes do medo de adoecer, foco básico da atual dietoterapia. Em relação ao hábito alimentar saudável, verificou-se que a maioria dos discursos mostram conceitos próximos ao senso comum, ou mesmo uma visão reducionista gerada pela formação biomédica ainda persistente na formação do nutricionista.

Podemos dizer que este estudo foi o início de uma avaliação sobre as influências do estudo da ciência da nutrição sobre o hábito alimentar do estudante. Tornam-se necessários aprofundamentos nesse tema, para compreender sobre a complexa influência dos conhecimentos adquiridos durante a formação acadêmica, principalmente na área da saúde, como motivação extrínseca para mudança de hábito alimentar das pessoas.

Muitos estudos mostram que o hábito alimentar sofre diversas influências, mas poucos descrevem sobre a interferência da formação acadêmica do indivíduo, e quando o fazem, remetem à frequência dos transtornos alimentares dizendo que profissionais de saúde têm mais chance de desenvolver a doença. 
Nesse estudo, percebemos a necessidade de rever a forma como são estruturados e abordados os estudos da ciência da nutrição, que por predominar a abordagem biomédica, foi promotora de uma relação de medo ao condicionar causa biológica com nutriente causador de doença. Nessa perspectiva, avaliar a percepção dos estudantes em relação ao que seja saudável, desde o início do curso, acompanhando por diferentes semestres, pode ser ferramenta interessante para estudos na área de educação alimentar e nutricional no que tange os significados e representações sociais da alimentação.

\section{REFERÊNCIAS BIBLIOGRÁFICAS}

ALVES, H. J; BOOG, M. C. F.

Comportamento alimentar em moradia estudantil: um espaço para a promoção da saúde. Rev. Saúde Pública, São Paulo, v. 41, supl. 2, p. 197-204, 2007.

ALVES, H. J; BOOG, M. C. F. Promoção de Saúde e Comensalidade: Um Estudo entre Residentes de Moradia Universitária. Rev. Segurança Alimentar e Nutricional,

Campinas, v. 13, supl. 2, p. 43-53, 2006.

BARDIN, L. Análise de conteúdo. Tradução: Luís Antero Reto e Augusto Pinheiro. São Paulo, SP: Edições 70, (1977), $1^{\text {a }}$ reimpressão da $1^{\mathrm{a}}$ edição de 2011.
BORGES, C. M.; LIMA FILHO, D. O.

Hábitos alimentares dos estudantes universitários: um estudo qualitativo. In.: VII Seminário em Administração, FEA - USP, Agosto de 2004. 15p. Disponível em: http//www.ead.fea.usp.br/semead/7semead Acesso em nov. 2011.

BOSI, M. L. M. A nutrição na concepção científica moderna: em busca de um novo paradigma. Rev. Nutriçãa. Puccamp, Campinas, v. 7, supl. 1, p. 32-47, jan./jun. 1994.

\section{COSTA, N. S. C. A formação do}

nutricionista: educação e contradição.

Goiânia: UFG, 2000. 151 p.

FREITAS, M.C.S. Educação nutricional e alimentar: algumas considerações sobre o discurso. In: FREITAS, M.C.S.; FONTES, G.A.V.; OLIVEIRA, N. (orgs). Escritas $e$ narrativas sobre alimentação e cultura, Salvador: EDUFBA, 2008. p. 305-311.

GARCIA, R. W. D.; CANESQUI, A. M. Antropologia e nutrição: um diálogo possível, Rio de Janeiro, Editora Fiocruz, 2005.

JACOBSON, M.S. Nutrição na adolescência. Anais Nestlé, São Paulo, v.55, n.24, p.24-33, 1998. 
MARTINS, M. C. F. N., BÓGUS, C. M.

Considerações sobre a metodologia

qualitativa como recurso para o estudo das ações de humanização em saúde. Saúde e

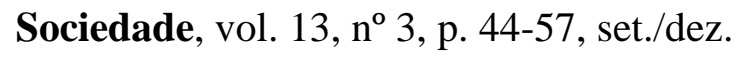
2004.

MORGANA, C. M.; VECCHIATTIA, I. R.;

NEGRÃO, A. B. Etiologia dos transtornos

alimentares: aspectos biológicos, psicológicos

e sócio-culturais. Rev. Bras. Psiquiatria,

São Paulo, v. 24, supl. 3, p. 18-23, dez. 2002.

NASCIMENTO, A. B. Comida: prazeres,

gozos e transgressões. Salvador: EDUFBA,

2007. 290 p.

REZENDE, E. G. et al. Educação Nutricional

e a cultura como questão. Rev. Ponto e

Vírgula, São Paulo, vol. 10, p 89-100, 2011.

ROMANELLI, G. O significado da

alimentação na família: uma visão

antropológica. Medicina, Ribeirão Preto. V.

39, n 3, p. 333-339, jul./set. 2006

SANTOS, C. R. A. A Alimentação e seu

lugar na História: Os Tempos da Memória

Gustativa. História: Questões \& Debates,

Curitiba, n. 42, p. 11-31, 2005.
SILVA, D. O.; RECINE, E. G. I. G.;

QUEIROZ, E. F. O. Concepções de

profissionais de saúde da atenção básica sobre

a alimentação saudável no Distrito Federal,

Brasil. Cad. Saúde Pública, vol.18, n.5,

p.1367-1377, 2002.

STRAUB, R. O. Psicologia da Saúde: Uma abordagem biopsicossocial. Trad. Ronaldo Cataldo. Porto Alegre: ArtMed, 2005.

VIEIRA, V. C. R. et al. Perfil

socioeconômico, nutricional e de saúde de adolescentes recém-ingressos em uma universidade pública brasileira. Rev.

Nutrição, Campinas, vol.15, n.3, Set.2002. 